\title{
Carta abierta a los miembros de la Sociedad Chilena de Enfermedades Respiratorias
}

\author{
Open letter to all Chilean Society of Respiratory Diseases' members
}

Me dirijo a ustedes a poco más de tres meses de haber asumido -en diciembre de 2017-el cargo de presidente de la Sociedad Chilena de Enfermedades Respiratorias (SER). Desde esta nueva responsabilidad, a la que me estoy dedicando sin ninguna experiencia previa, salvo haber sido vicepresidente de la SER en el bienio anterior, me he ido compenetrando cada vez más de su funcionamiento y de mis obligaciones.

Destaco el compromiso de las personas que dedican tiempo de otras actividades y obligaciones para aportarlo a la SER, sin otra motivación que contribuir para que la SER cumpla con su 'misión'. Ellos son los directores en ejercicio, el Comité Científico, el Comité Editorial de la Revista, todos los coordinadores y miembros de las diferentes Comisiones, los coordinadores de cursos y jornadas, dentro y fuera de Santiago, los miembros de las filiales de regiones y los coordinadores del Congreso Anual. Un especial reconocimiento para todo nuestro personal que trabaja en la sede de la SER: Sra. Angélica Poblete, Sra. Ana María Muñoz, Sr. Oscar Osses y Sra. Miriam Mardones. Es probable que omita los aportes de muchas personas de la SER, pero hoy les reconozco su entrega y les agradezco su generosidad.

Al asumir la presidencia de la SER, me cabe la responsabilidad de mantener y elevar -en lo posible- el nivel científico de la Sociedad, de nuestros cursos y congresos, una de las principales fuentes de información médica actualizada con la que contamos los profesionales de la salud y miembros de la SER, sean ellos médicos, kinesiólogos, tecnólogos médicos o enfermeras. Además, participar de estas actividades, nos permite interactuar como personas y conocernos en un plano personal que otras actividades de perfeccionamiento no lo permiten. Las reuniones para especialistas (Jornadas de Otoño y Congreso anual) constituyen nuestras principales acciones para que nuestros socios, sin salir de nuestro país, reciban la visita de expertos de alto nivel, conozcamos de su experiencia y sabiduría $y$ podamos compartir e interactuar con ellos en un plano de mayor cercanía y amistad. Los diferentes convenios suscritos en años anteriores por mis predecesores entre la SER y ALAT (Asociación Latino-Americana de Tórax), ERS (European Respiratory Society) y SEPAR (Sociedad Española de Neumología y Cirugía Torácica), han permitido contar cada vez con más especialistas de primer nivel provenientes de América Latina y Europa para lograr el propósito académico de actualizar el conocimiento en ciencias bio-médicas de nuestros socios.

Los desafíos, además de los cursos, jornadas y congresos, son mantener la viabilidad financiera de la Sociedad, que se nutre de los aportes mensuales de los socios, más los apoyos fundamentales de casas farmacéuticas, que ven en nosotros una Sociedad seria y comprometida con la salud respiratoria de nuestra población. Ese respaldo generoso permite el funcionamiento de la SER en forma sana.

Los desafios que veo y asumo son muchos:

1. Revista de la Sociedad. Necesitamos mejorar y aumentar los aportes de artículos a nuestra revista, lo cual supone el compromiso como Sociedad y como socios individuales, de hacer aportes a la misma, contribuyendo con dar a conocer nuestras lineas de investigación, casos clínicos de interés o revisiones de temas de actualidad. Las comisiones están invitadas a hacer los aportes generados por sus actividades anuales, los cuales siempre serán bienvenidos.

Del mismo modo en que pido su cooperación para enviar artículos, les solicito su ayuda para actuar como revisores de artículos, cumpliendo con esta responsabilidad dentro de los plazos que se les solicitan. Sólo de esta manera ustedes contribuirán de manera concreta a elevar el nivel científico de nuestra revista. 
2. Página WEB. La sociedad tiene que mejorar la comunicación con sus socios y modernizar su plataforma tecnológica para que la página WEB sea un punto de encuentro para informarnos de novedades, cursos, buscadores de revistas e información cientifica. Necesitamos crear sistemas de redes sociales, que hoy casi todo el mundo usa. Desde ya invitamos a sumarse a este desafio y quienes quieran contribuir, lo pueden hacer desde ahora mismo.

3. Cursos "online". La sociedad tiene la obligación de actualizar los tres cursos "on line" que dicta actualmente: Asma, EPOC y Rehabilitación, así como también crear nuevos cursos. Es prioritario que en aquellas ciudades donde no tenemos cursos con la modalidad presencial, nuestros socios y los médicos de atención primaria, puedan realizar cursos de la Sociedad. Estudiaremos de qué manera este anhelo se puede concretar.

4. Guías de cáncer. Existe el mayor interés de generar las primeras guías de cáncer pulmonar, impulsadas por la SER, pero reuniendo a todas las especialidades vinculadas con cáncer de pulmón, como son médicos clínicos, broncopulmonares, radiólogos, neumólogos intervencionales, anátomopatólogos, cirujanos de tórax, oncólogos, radioterapeutas y médicos de cuidados paliativos. La sola idea de concretar este proyecto ha despertado enorme interés y agradezco el esfuerzo de la Comisión de Cáncer que está impulsando esta iniciativa.

5. Cursos de la SER y sus filiales. Tenemos el compromiso de mantener y mejorar los cursos actuales, consolidar el curso del Norte (Antofagasta) y crear nuevos cursos en regiones impartidos por la SER con la ayuda de sus socios para extender y difundir los conceptos básicos a nuestros especialistas y médicos generales de diferentes ciudades de Chile, a fin de mantenerlos actualizados y así sumar nuestros esfuerzos para que ellos puedan ofrecer una medicina de la mejor calidad.

6. Relación con casas farmacéuticas. Vivimos tiempos de cambio, donde nuestro trabajo y cualquier relación con la industria es mirada con suspicacia por la población general. Es nuestro deber cuidar y velar por una relación transparente y clara con la industria, donde ambos actores nos necesitamos mutuamente, pero hoy con reglas más claras que antes.

No son pocos los desafios para los siguientes dos años. He tratado de organizar mi tiempo para que cada una de estas ideas no sean sólo intenciones, sino logros concretos de esta gestión que me corresponde encabezar.

Dr. Hernán Cabello Araya

Presidente Sociedad Chilena de Enfermedades Respiratorias Email:ser@serchile.cl 